\title{
A Declaração do Estado de Coisas INCONSTITUCIONAL FRENTE ÀS CONSEQUENTES EXTERNALIDADES NEGATIVAS
}

\section{The Declaration of the Unconstitutional State of Affairs Against the Conseguent Negative EXTERNALITIES}

\section{La Declaración del Estado de Cosas InCONSTITUCIONAL FRENTE a LAS CONSECUENTES EXTERNALIDADES NEGATIVAS}

André Luis Cateli Rosa* Valter Moura do Carmo**

1 Introdução. 2 Direito e economia como sistema de referência. 3 Externalidades. 3.1 Externalidades positivas. 3.2 Externalidades negativas. 3.3 Controle das externalidades. 3.4 Externalidades pela análise econômica do direito. 4 Direitos sociais. 5 O Estado de Coisas Inconstitucional. 5.1 Origem: Corte Constitucional Colombiana. 5.2 Aplicação no Peru. 5.3 Aplicação no Brasil. 6 A inviabilidade do Estado de Coisas Inconstitucional. 7 Conclusão. Referências.

* Assessor Jurídico do Banco do Brasil S/A, Advogado e Administrador. Doutorando em Direito pela Universidade de Marília. Mestre em Direito pelo Centro Universitário Eurípides de Marília, onde leciona nos cursos de Pós-Graduação. Especialista em Liderança e Coaching para Gestão de Pessoas. Professor dos Cursos de Administração e Ciências Contábeis das Faculdades Integradas de Ourinhos - FIO. E-mail: <andrerosaadv@yahoo.com.br>.https://orcid.org/0000-0003-3670-7836

** Possui graduação em Direito pela Universidade de Fortaleza - UNIFOR; mestrado em Direito Constitucional pela UNIFOR com período sanduíche na Universidade Federal de Santa Catarina - UFSC e doutorado em Direito pela UFSC, tendo realizado o doutorado sanduíche na Universidade de Zaragoza (Espanha) com bolsa do PDSE da CAPES e período de investigação na Universidade Federal da Paraíba - UFPB com bolsa do PROCAD da CAPES. Realizou estágio de pós-doutorado na Universidade de Marília - UNIMAR com bolsa do PNPD da CAPES. Atualmente é professor do mestrado e doutorado em Direito da UNIMAR. Diretor de relações institucionais do CONPEDi. Membro da Comissão de Estudo de Identificação e Descrição da ABNT. Editor da Estudos: Revista de Ciências Humanas e Sociais Aplicadas da UNIMAR e editor-adjunto da Revista do Instituto Brasileiro de Direitos Humanos. E-mail: <vmcarmo86@gmail.com>. http://orcid. org/0000-0002-4871-0154 


\title{
RESUMO
}

O presente artigo visa a abordar a validade da teoria do Estado de Coisas Inconstitucional frente ao ordenamento jurídico pátrio. Para tanto, demonstra a gênese dessa teoria por meio de sua aplicação pela Corte Constitucional colombiana e a forma pela qual foi acolhida pelo Supremo Tribunal Federal, tudo levando em consideração fundamentos da República Federativa do Brasil, consagrados pela Constituição Federal, tais como democracia e igualdade, sem prejuízo de análise da eficiência, da qual devem se revestir todas as decisões da administração pública. Com o intuito de se verificar a validade da teoria diante dos termos propostos, utiliza como sistema de referência "Direito e Economia", que analisa as externalidades proporcionadas em função da aplicação das leis e orienta para que se concretize da forma que proporcione maior eficiência, levando-se em consideração o diálogo entre Direito e Economia, sem prejuízo de se observar o ordenamento jurídico vigente. Destarte, uma criteriosa revisão de literatura e jurisprudência foi utilizada no estudo. Tais consequências são apresentadas na investigação, vinculadas à apreensão da análise econômica do Direito, às externalidades, aos direitos sociais e ao Estado de Coisas Inconstitucional. Após a análise pontual de tais institutos, procedeu-se com sua integração para sobejar a presente proposta interpretativa, núcleo vital deste estudo. $\mathrm{O}$ raciocínio teleológico, portanto, progride rumo à mescla desses institutos. Em conclusão, verificou-se que a teoria encontra obstáculos para prosperar frente aos dispositivos que balizam a Constituição Federal de 1988.

Palavras-chave: Democracia. Direito e Economia. Direitos sociais. Estado de Coisas Inconstitucional. Externalidades.

\begin{abstract}
The present article addresses the validity of the Unconstitutional State of Affairs theory in regards to the Brazilian legal system. In order to do so, it demonstrates the inception of this theory through its application by the Colombian Constitutional Court and the way through which it was received by the Brazilian Federal Supreme Court, by taking into account the foundations of the Federative Republic of Brazil, enshrined by its Federal Constitution, such as democracy and equality, and includes an analysis of its efficiency, which is something that should characterize all the decisions of the public administration. In order to verify the validity of the theory in relation to the proposed terms, the postulates of "Law and Economics" are used as a reference system, which analyses the externalities provided by the application of the law and aims at guiding it towards an application that provides greater efficiency and takes into account the dialogue between Law and Economy, without detracting from observing the current legal system. Thus, this study carries on a careful review of the literature and jurisprudence. These consequences are presented in this investigation, linked to the apprehension of the economic analysis of Law, to externalities, to social rights
\end{abstract}


and to the Unconstitutional State of Affairs. After the punctual analysis of these institutes, we proceeded with their integration to complete the present interpretative proposal, which is the vital core of this study. The teleological reasoning, therefore, progresses towards the merger of these institutes. In conclusion, it was verified that the theory finds obstacles to thrive because of the devices that mark the Federal Constitution of 1988.

Keywords: Democracy. Law and Economics. Social Rights. Unconstitutional State of Affairs. Externalities.

\section{RESUMEN}

El presente artículo tiene por objeto abordar la validez de la teoría del Estado de Cosas Inconstitucional frente al ordenamiento jurídico patrio. Para eso, demuestra la génesis de esta teoría por medio de su aplicación por la Corte Constitucional colombiana y la forma en que fue acogida por el Supremo Tribunal Federal brasileño, todo eso teniendo en cuenta fundamentos de la República Federativa del Brasil, consagrados por la Constitución Federal, como democracia e igualdad, sin perjuicio del análisis de la eficiencia, que debe revestir todas las decisiones de la administración pública. Con el propósito de verificar la validez de la teoría ante los términos propuestos, los postulados de "Derecho y Economía" son utilizados como el sistema de referencia, que analiza las externalidades proporcionadas en función de la aplicación de las leyes y orienta para que se concretice de forma que proporcione más eficiencia, teniendo en cuenta el diálogo entre Derecho y Economía, sin dejar de observar el ordenamiento jurídico vigente. De esta manera, una cuidadosa revisión de literatura y jurisprudencia fue utilizada en el estudio. Tales consecuencias se presentan en la investigación, vinculadas a la aprehensión del análisis económico del Derecho, a las externalidades, a los derechos sociales y al Estado de Cosas Inconstitucional. Después del análisis puntual de tales institutos, se procedió con su integración para completar la presente propuesta interpretativa, núcleo vital de este estudio. El raciocinio teleológico, por lo tanto, progresa hacia la mezcla de esos institutos. En conclusión, se verificó que la teoría encuentra obstáculos para prosperar frente a los dispositivos que balizan la Constitución Federal de 1988.

Palabras clave: Democracia. Derecho y Economía. Derechos Sociales. Estado de Cosas Inconstitucionales. Externalidades.

\section{INTRODUÇÃO}

A teoria do Estado de Coisas Inconstitucional firmou sólida jurisprudência na Colômbia por meio das decisões SU.559/97 e T-153/98 proferidas por sua Corte Constitucional. Referida teoria, quando absorvida pelo Poder Judiciário, consiste na imposição de obrigações de fazer aos demais poderes do Estado quando identificada inércia em promover a entrega daqueles 
direitos que envolvem prestações positivas de sua parte, os direitos sociais, classificados pela doutrina como direitos fundamentais de segunda geração.

Essa teoria ganhou espaço junto ao ordenamento jurídico brasileiro quando do pronunciamento do Supremo Tribunal Federal nos autos do RE no 592.581 e da ADPF n 347, com os respectivos entendimentos de que é lícito ao Judiciário impor à Administração Pública obrigação de fazer, para fins de realização de obras ou reformas emergenciais em presídios para garantir os direitos fundamentais dos presos, como sua integridade física e moral, bem como determinar a liberação de recursos acumulados no Fundo Penitenciário Nacional, abstendo-se de outros contingenciamentos.

Diante desse contexto, parece apropriado questionar: levando-se em consideração os aspectos da democracia e da tripartição dos poderes, consagrados pela Constituição Federal de 1988, é lícito ao Poder Judiciário impor obrigações de fazer aos demais poderes do Estado?

Dessa forma, a necessidade de se garantir a segurança jurídica e os princípios que figuram como pilares da Constituição Federal e do próprio Estado Democrático de Direito justificam um estudo aprofundado sobre o tema, com o intuito de se demonstrar a validade ou não da intervenção do Poder Judiciário frente aos demais poderes do Estado.

Para tanto, utiliza-se do sistema de referência "Direito e Economia", que analisa as externalidades proporcionadas em função da aplicação das leis e orienta para que se concretize da forma que proporcione maior eficiência, levando-se em consideração o diálogo entre Direito e Economia, sem prejuízo de se observar o ordenamento jurídico vigente.

Nesse contexto, primeiramente aborda-se em que consiste o sistema de referência "Direito e Economia" e como ele será aplicado no presente estudo, de forma que, na sequência, apresentam-se as externalidades a serem consideradas na aplicação das leis, segundo ele.

Em prosseguimento, apresenta-se o conceito dos direitos sociais com foco naqueles que pressupõem prestações positivas do Estado, que são objeto das decisões judiciais aventadas no presente estudo, de forma que, em seguida, por meio do capítulo quarto, esclarece no que consiste o estado de coisas inconstitucional, trazendo a sua origem e a forma pela qual é aplicado atualmente no cenário nacional.

Finalmente, aborda-se a validade da teoria do Estado de Coisas Inconstitucional frente ao sistema de referência utilizado, levando-se em consideração fundamentos da República Federativa do Brasil, consagrados pela Constituição Federal, tais como democracia e igualdade, sem prejuízo da eficiência, da qual deve se revestir todas as decisões da administração pública.

Para obtenção dos resultados perseguidos, destarte, uma criteriosa revisão de literatura e jurisprudência foram preceitos básicos do estudo. Tais consequências são apresentadas na investigação, vinculadas à apreensão da análise econômica do Direito, às externalidades, aos direitos sociais e ao Estado de Coisas Inconstitucional. Após a análise pontual de tais institutos, procedeu-se com sua integração para sobejar a presente proposta interpretativa, núcleo vital deste estudo. $\mathrm{O}$ raciocínio teleológico, portanto, progride rumo à mescla destes institutos. 
Em conclusão, verificou-se que a teoria do Estado de Coisas Inconstitucional não possui validade frente aos dispositivos que balizam a Constituição Federal de 1988, tendo em vista que sua implementação resulta em externalidades negativas por ela não amparada e reprovada pela análise econômica do Direito.

\section{DIREITO E ECONOMIA COMO SISTEMA DE REFERÊNCIA}

O diálogo entre Direito e Economia é essencial para oferecer as melhores soluções para a sociedade em qualquer tempo, principalmente nos tempos atuais, em que essas ciências, cada vez mais, se relacionam.

Questão que sempre surge quando se refere à relação entre Direito e Economia é a busca do bem-estar social. A regulação da Economia pelo Direito somente pode ocorrer de forma racional caso haja um profundo estudo e conhecimento das relações econômicas as quais se pretende regular. Sem um estudo prévio e conhecimento das relações econômicas, pode-se chegar a um estado de super-regulação, resultando num contexto em que a positivação e a aplicação do Direito podem inviabilizar o melhor desenvolvimento das atividades econômicas, resultando em desinteresse em investimentos e inovações, ocasionando atraso na evolução da sociedade. Pode-se afirmar ainda que a ausência de prévia e competente análise da Economia pelo Direito, no bojo da inserção e da aplicação de normas, pode inviabilizar as atividades econômicas no médio e no longo prazo.

Levando-se ainda em consideração que as pessoas agem racionalmente, é importante destacar que incentivos externos certamente conduzirão a comportamentos em busca de prêmios ou para afastar punições. Nessa seara, tem-se que o Direito deve ser considerado um incentivo externo à Economia, vez que, da forma como positivado e aplicado, pode levar as pessoas a atuarem de maneiras diversas frente à exploração da atividade econômica. Sendo assim, se positivado ou aplicado sem levar em consideração os aspectos econômicos, pode inibir essa atividade caso pressuponha punições para aqueles que, de alguma forma, queiram desenvolvê-la, da mesma forma que pode estimulá-la, caso pressuponha prêmios para aqueles que a explorem. Nesse sentido, na esteira da evolução da sociedade, a análise das relações econômicas certamente levará à possibilidade de formulação e aplicação das normas jurídicas de forma que possibilitem cada vez mais torná-las mais eficientes sob a ótica de se obter um melhor desempenho econômico da nação, refletindo em consequente bem-estar social.

A utilidade da análise econômica do Direito consiste em encontrar a racionalidade de toda e qualquer decisão, independente de estar dentro ou fora do mercado, tendo em vista que toda a atividade humana não instintiva se abarca nesse conceito e pode, por isso, ser economicamente analisada (SCHMIDT, 2014, p. 206).

Assim, o método que leva em conta a Economia para a análise e a aplicação do Direito, considerando a interação entre o pensamento econômico e o Direito, passa a ganhar força e se consolida por meio dos estudos realizados por Richard A. Posner. 
Posner entende que o Direito deve ser interpretado e pensado a partir dos princípios da Economia. Iniciando por uma lógica pragmática, defende um método de interpretação consequencialista para o Direito, transformando-o num instrumental pautado pelos efeitos das decisões jurídicas. Nesse contexto, esclarece que as decisões judiciais devem ser orientadas pelo padrão de análise custo-benefício, o qual denomina maximização da riqueza, representando este um verdadeiro princípio ético-comportamental (POSNER, 2010, p. 14).

Sustenta que o Poder Judiciário deve ser previsível e estável para oferecer ao mercado segurança para o livre fluxo dos recursos. As decisões judiciais devem, pois, estar livres de subjetividades valorativas decorrentes da lógica jurídica principiológica e se pautarem pela diretriz da eficiência na alocação de recursos.

Nesse contexto, a perda de recursos/esforços representa um custo social, o que é indesejável sob qualquer perspectiva, de forma que a utilização do Direito na produção e a aplicação de normas devem visar ao alcance do melhor resultado econômico com o mínimo de erros ou perdas, o que resultará na obtenção de melhor rendimento e alcance dos objetivos de maneira mais produtiva, tornando nítida a necessidade de se considerar a relação existente entre Direito e Economia.

Assim, pode-se afirmar que o Direito é um sistema aberto que influi e é influenciado pelas instituições sociais existentes na comunidade em que se aplica. Por isso, defensores da teoria evolucionista das sociedades admitem que o conjunto de regras socialmente predispostas serve à organização das relações intersubjetivas e, em dado momento, se consagra como Direito posto. Assim, fatores econômicos estarão envolvidos no processo de criação e aplicação das normas (ZYLBERSZTAJN; STAJN, 2005, p. 83).

É sob essa perspectiva que será analisado o Estado de Coisas Inconstitucional, tendo em vista as externalidades que podem resultar de sua declaração pelo Poder Judiciário.

\section{EXTERNALIDADES}

Externalidades são os efeitos sociais, econômicos e ambientais indiretamente causados pela ação de um agente que, de alguma forma, participa desse contexto, ou seja, ocorre quando o bem-estar de uma determinada pessoa é afetado em função de decisões tomadas por outra(s) pessoa(s).

A questão das externalidades tem sido estudada de forma multidisciplinar, cada área ressaltando seus próprios interesses e analisando o problema com uma ótica distinta.

No que tange ao aspecto econômico, as externalidades ocorrem quando os agentes econômicos interagem no mercado, gerando, de alguma forma, malefícios ou benefícios para indivíduos alheios ao processo.

Nusdeo (2012, p. 19) a define como "custos ou benefícios cujos ônus ou vantagens recaem sobre terceiros, não participantes de uma relação de mercado."

Ensina Nusdeo (1975, p. 124), que: 
Em suma, os efeitos externos ou externalidades representam benefícios ou custos que se transferem de umas unidades do sistema econômico para outras para a comunidade como um todo, extra-mercado, isto é, este não tem condições para captá-los, para equacionar o seu processo de troca e de circulação. Daí o nome de custo social dado também ao efeito externo negativo ou deseconomia externa. Na realidade, ele é um custo que deixa de ser incorrido pela unidade que o gerou, por aquele que conduz a atividade à qual serviu. Ele deixa assim de ser privado, para recair indiretamente sobre terceiros que poderão vir a ser identificados ou não.

Complementa o mesmo autor (NUSDEO, 2015, p. 124) em outra de suas obras, esclarecendo que:

As externalidades correspondem, pois, a custos ou benefícios circulando externamente ao mercado, vale dizer, que se quedam incompensados, pois, para eles, o mercado, por limitações institucionais, não consegue imputar um preço. $\mathrm{E}$, assim, o nome externalidade ou efeito externo não quer significar fatos ocorridos fora das unidades econômicas, mas sim fatos ou efeitos ocorridos fora do mercado, externos ou paralelos a ele, podendo ser vistos como efeitos parasitas.

No mesmo sentido é o entendimento de Motta (1997, p. 224) ao explanar que:

As externalidades estão presentes sempre que terceiros ganham sem pagar por seus benefícios marginais ou percam sem ser compensados por suportarem o malefício adicional. Assim, na presença de externalidades, os cálculos privados de custos ou benefícios diferem dos custos ou benefícios da sociedade. Assim, externalidade existe quando o bem-estar de um indivíduo é afetado, não só pelas suas atividades de consumo como também pelas atividades de outros indivíduos.

Dessa forma, tem-se que as externalidades podem ser positivas (quando há ganhos sem pagamento por seus benefícios marginais) ou negativas (quando há perdas em função de um malefício adicional sem serem compensadas), tudo em função de atividades de outros indivíduos cujos atos não se comunicam diretamente com esses que ganham ou perdem.

\subsection{EXTERNALIDADES POSITIVAS}

Externalidades positivas são benefícios acarretados a alguém sem qualquer compensação ao seu gerador. Podem-se citar, como exemplos, as consequências econômicas positivas que ocorrem quando uma empresa desenvolve um método de produção ou administração de baixo custo que é absorvido gratuitamente por outra empresa ou quando um fazendeiro preserva uma área florestal que favorece gratuitamente a proteção do solo de outros fazendeiros.

Nusdeo (2015, p. 127) exemplifica trazendo à baila que a "florada das maçãs" exerce efeito positivo sobre a produção de mel. Ressalta ainda que uma criação de abelhas, além de produzir o mel e gerar alimento e recursos monetários para o produtor, gera a importante externalidade positiva de polinização das plantas.

Ou seja, ganhos sem pagamento por seus benefícios marginais, tudo em função de atividades de outros indivíduos cujos atos não se comunicam diretamente com esses que ganham. 


\subsection{EXTERNALIDADES NEGATIVAS}

Externalidades negativas são aquelas que causam um custo para alguém, determinado ou indeterminado, sem que o tenham ocasionado.

Um exemplo é a degradação ou exaustão de recursos ambientais decorrentes das atividades de produção e consumo de certos bens que prejudicam a saúde humana e a produção de outros bens que também destroem a fauna e flora (MOTTA, 1997, p. 224).

Podem-se mencionar, como exemplos, ainda, o caso de uma fábrica que produz fumaça que é prejudicial para a vizinhança; uma indústria que despeja seus resíduos líquidos poluentes em um rio, de onde os pescadores retiram os peixes para sobreviver; a desvalorização imobiliária decorrente da poluição sonora de que são vítimas as famílias que residem perto de grandes avenidas e viadutos, etc.

Ou seja, perdas em função de um malefício sofrido por pessoas sem serem compensadas, tudo em função de atividades de outros indivíduos cujos atos não se comunicam diretamente com esses que perdem.

\subsection{CONTROLE DAS EXTERNALIDADES}

O fenômeno do controle de externalidades envolve o controle desses fatores externos positivos ou negativos que influenciam na Economia, o que pode ser feito por meio da elaboração e da aplicação de leis. Em condições de normalidade (neutralidade), o pressuposto é que o equilíbrio de mercado, na ausência da norma, tenha as propriedades do cenário tido por ideal. Todavia, esse equilíbrio externo exige tempo para que aconteça, de forma que, por meio das leis e da regulação de externalidades, possa-se alcançar esse equilíbrio com maior rapidez.

Pertinente exemplo é o aumento no valor das locações residenciais, causado por um grande aumento de demanda. O equilíbrio pelo mercado exige tempo, pois demandaria novas construções de imóveis (o que seria interessante em função dos altos preços das locações), resultando no aumento de oferta de imóveis para locação até que se reencontre o equilíbrio de longo prazo. Todavia, caso o legislador opte por proteger os inquilinos congelando o valor das locações residenciais, afastará o cenário ideal, exercendo o controle de externalidades (aumento da demanda que, por via reflexa, aumenta o valor do aluguel) por meio da edição de leis (que congelam o preço dos aluguéis).

A ação eficiente no controle de externalidades se torna importante parâmetro de análise e de aplicação dos princípios econômicos ao Direito, apresentando-se como critério a ser utilizado pelos juristas. Destaque aos conceitos de eficiência de Pareto e Kaldor-Hicks.

Inserida nesse contexto, a busca pela maximização da eficiência que resulte no controle de externalidades envolve o estudo das leis e sua aplicação, tendo por propósito o uso da Teoria Econômica para recomendar como as leis devem ser criadas e impostas para que induzam os agentes a agir de forma eficiente. Utiliza-se o critério de eficiência de Pareto junto com todas as outras premissas da Economia neoclássica. 
Segundo a eficiência de Pareto, a modificação de um quadro será superior ao anterior estado de coisas, se dela resultar benefício para ao menos um sujeito, sem gerar prejuízo para outros.

Pode-se abordar a eficiência também pela mera "maximização de ganhos e minimização de custos" e, sob essa ótica, uma situação será eficiente se a única maneira de elevação dos benefícios for, também, o aumento dos custos.

Já a maximização da eficiência pelo critério de Kaldor-Hicks é aquela pela qual há situações em que os prejuízos impostos por dada alteração podem ser objeto de uma compensação. Nesses casos, deve-se considerar como melhoria aquelas modificações que redundem em benefícios para alguns e piora para outros, desde que haja a possibilidade de os primeiros realizarem a compensação necessária para a satisfação dos prejudicados. O que se analisa é o efeito líquido global da alteração, de modo que, se o excedente gerado em favor dos beneficiados permitir, além da melhoria da utilidade destes, a compensação dos prejudicados, essa alteração será considerada mais eficiente que a situação pretérita, segundo tal critério (PINHEIRO; SADDI, 2005, p. 121).

Dias (2009) destaca que, em relação à análise econômica do Direito, essa busca pela eficiência pode ser aplicada também à administração pública. Todavia, critica a adoção da regra da Superioridade de Pareto em função de suas evidentes limitações, esclarecendo que:

Diante da complexidade das relações que envolvem a atuação da Administração Pública, os seus atos acabam por gerar ganhadores e perdedores indeterminados, sendo impossível verificar todas a variáveis e situações particulares que decorrem da atuação administrativa e, em razão disto, é impossível constatar empiricamente o respeito à regra da Superioridade de Pareto (DIAS, 2009, p. 77).

Da mesma forma, Dias (2009) tece críticas ao modelo de superioridade de Kaldor-Hicks, tendo em vista que:

Um determinado ato da Administração pode resultar em grande lucro econômico de uma pessoa e, por outro lado, comprometer a tranquilidade e a segurança de outras, gerando resultados que não podem ser comparados para se verificar a possibilidade de compensação potencial (DIAS, 2009, p. 78).

Na sequência de seu raciocínio, Dias coaduna com o entendimento lançado por Richard Posner na obra Análise Econômica do Direito, em função do qual, tendo em vista o modelo econômico que atualmente prevalece no mundo, a eficiência equipara os países a grandes empresas, passando a exigir-lhes viabilidade econômica, que seria apurada por meio da cotação de seus títulos da dívida pública, ou mesmo pelo índice de risco de neles investir.

Dessa forma, esclarece que "a governabilidade de um país passou a ser associada à sua eficiência econômica, libertando-se de mandamentos anteriormente apregoados pelo Estado de Bem-Estar, no qual caberia ao Poder Estatal suprir as necessidades de seus cidadãos." (DIAS, 2009, p. 82).

É nesse contexto que as externalidades são tratadas pela análise econômica do Direito, conforme será demonstrado. 


\subsection{EXTERNALIDADES PELA ANÁLISE ECONÔMICA DO DIREITO}

A noção de externalidade proposta pela análise econômica do Direito tem origem no trabalho de Coase, que propõe analisá-la a partir da noção de custo de oportunidade, uma análise comparativa entre a receita obtida de uma dada combinação de fatores e as possibilidades de receitas que seriam obtidas com arranjos alternativos. Assim, em vez de tratar os fatores de produção como coisas, Coase $(1960$, p. 2) propõe considerá-los como direitos.

Nesse sentido, o direito de fazer algo que produza um dano para outros também pode ser visto como um fator de produção, ou seja, o custo de exercer esse direito (de usar um fator de produção) é sempre uma perda para quem sofre os efeitos do seu exercício.

Dessa forma, Coase $(1960$, p. 2) inverteu os termos em que a questão era tradicionalmente considerada, atribuindo-lhe uma abordagem dual. Segundo ele:

A abordagem tradicional tende a obscurecer a natureza da escolha que deve ser feita. A questão é geralmente considerada como aquela em que A proporciona dano sobre B e o que deve ser decidido é: como devemos restringir A? Mas isso é errado. Estamos lidando com um problema de natureza recíproca. Evitar o dano a B causaria dano em $\mathrm{A}$. A questão real que deve ser decidida é: deve ser permitido a A prejudicar B ou deve ser permitido a B prejudicar A? O problema é evitar o dano mais grave (COASE, 1960, p. 2, tradução nossa). ${ }^{1}$

Segue Coase (1960, p. 2) em seu raciocínio exemplificando da seguinte forma:

O problema dos gados que escapam e destroem lavouras em terras vizinhas. Se é inevitável que algum gado escape, um aumento no suprimento de carne só pode ser obtido em detrimento de uma diminuição no fornecimento das lavouras. A natureza da escolha é clara: carne ou agricultura. E a resposta que deve ser dada não é óbvia, a menos que saibamos o valor do que é obtido, bem como o valor do que é sacrificado para obtê-lo (COASE, 1960, p. 2, tradução nossa). ${ }^{2}$

Nesse contexto o problema não é simplesmente evitar dano, mas sim evitar o dano maior. O que deve ser avaliado é se é viável, do ponto de vista da sociedade, permitir ou inibir a ação de "A", e a resposta não é óbvia, a menos que se conheçam os valores dos ganhos e perdas envolvidos na questão.

Essa conjuntura leva à conclusão de que as tomadas de decisões no momento da aplicação das leis devem levar em consideração todos os valores envolvidos na questão sob análise, direta e indiretamente, devendo-se considerar todas as externalidades.

1 No original: "The traditional approach has tended to obscure the nature of the choice that has to be made. The question is commonly thought of as one in which A inflicts harm on B and what has to be decided is: how should we restrain A? But this is wrong. We are dealing with a problem of a reciprocal nature. To avoid the harm to B would inflict harm on A. The real question that has to be decided is: should A be allowed to harm B or should B be allowed to harm A? The problem is to avoid the more serious harm."

2 No original: "the problem of straying cattle which destroy crops on neighbouring land. If it is inevitable that some cattle will stray, an increase in the supply of meat can only be obtained at the expense of a decrease in the supply of crops. The nature of the choice is clear: meat or crops. What answer should be given is, of course, not clear unless we know the value of what is obtained as well as the value of what is sacrificed to obtain it." 


\section{DIREITOS SOCIAIS}

Historicamente, o avanço do capitalismo e a sedimentação da política liberal ocasionaram o crescimento das desigualdades sociais, tudo sob referendo das instituições. Nesse sentido, o constante conflito existente entre as classes dos patrões e dos operários estimulou a organização destes últimos, que passaram a exercer pressão cada vez maior frente ao Estado para que houvesse o reconhecimento de direitos que assegurassem a igualdade mínima de condições entre as pessoas, uma vez que de nada adiantaria ter liberdades (direitos fundamentais de primeira geração) sem garantias mínimas para seu exercício.

É nesse cenário que cresce a pressão para o reconhecimento dessas garantias por meio do ordenamento jurídico dos Estados, já que, conforme bem contextualiza Dallari (2004, p. 46), "não basta afirmar que todos são iguais perante a lei; é indispensável que sejam assegurados a todos, na prática, um mínimo de dignidade e igualdade de oportunidades."

É nesse contexto, então, que surgem os chamados direitos sociais, hodiernamente denominados de direitos fundamentais de segunda geração, que dizem respeito aos direitos de igualdade e visam à realização da justiça social, garantindo a liberdade por intermédio do Estado.

Traduzem uma etapa de evolução na proteção da dignidade humana. Sua essência é a preocupação com as necessidades do ser humano. Garantem uma forma de proteção à dignidade humana, objetivando assegurar a satisfação das necessidades mínimas para que se tenha dignidade e sentido na vida (ARAÚJO; NUNES JÚNIOR, 1999, p. 73).

Trata-se de desdobramento da perspectiva de um Estado Social de Direito. Seu reconhecimento encontra guarida, pela primeira vez, na Constituição Francesa de 1791 e, posteriormente, possui como documentos marcantes a Constituição mexicana de 1917, a de Weimar, na Alemanha, de 1919 e, no Brasil, a Constituição de 1934.

Nas palavras de Silva (2000, p. 289):

Assim, podemos dizer que os direitos sociais, como dimensão dos direitos fundamentais do homem, são prestações positivas proporcionadas pelo Estado direta ou indiretamente, enunciadas em normas constitucionais, que possibilitam melhores condições de vida aos mais fracos, direitos que tendem a realizar a igualização de situações sociais desiguais. São, portanto, direitos que se ligam ao direito de igualdade. Valem como pressupostos do gozo dos direitos individuais na medida em que criam condições materiais mais propícias ao auferimento da igualdade real, o que, por sua vez, proporciona condição mais compatível com o exercício efetivo da liberdade.

Dessa forma, os direitos sociais se apresentam como prestações positivas a serem implementadas pelo Estado e tendem a concretizar a perspectiva de uma isonomia substancial e social na busca de melhores e adequadas condições de vida.

Sarlet (2008, p. 304) destaca que os direitos sociais se encontram intimamente ligados às tarefas de melhoria, à distribuição e à redistribuição dos recursos existentes, assim como à criação de bens essenciais não disponíveis para todos que deles necessitam. 
Para Araújo e Nunes Júnior (1999, p. 146), os direitos sociais são aqueles que reclamam do Estado um papel prestacional de minoração das desigualdades sociais.

No Brasil, esses direitos se encontram consagrados como fundamentos da República Federativa (art. $1^{\circ}, \mathrm{IV}$, da CF/88), que assim dispõe: “Art. $1^{\circ}$. A República Federativa do Brasil, formada pela união indissolúvel dos Estados e Municípios e do Distrito Federal, constitui-se em Estado Democrático de Direito e tem como fundamentos: [...] IV - os valores sociais do trabalho e da livre iniciativa." (BRASIL, 1988, on-line).

Isso porque, na esteira do raciocínio aqui desenvolvido, a livre iniciativa, somente é possível, uma vez que sejam assegurados os direitos sociais, o que proporciona o mínimo de condições existenciais para o ser humano.

Não obstante sua consagração, no Brasil, a Constituição Federal de 1988 trouxe, de forma expressa, o reconhecimento dos direitos sociais em seu capítulo II, primeiramente por meio de rol prescrito no art. $6^{\circ}$, que assim dispõe: "São direitos sociais a educação, a saúde, a alimentação, o trabalho, a moradia, o transporte, o lazer, a segurança, a previdência social, a proteção à maternidade e à infância, a assistência aos desamparados, na forma desta Constituição." (BRASIL, 1988, on-line).

Além do caput do art. $6^{\circ}$, a Constituição Federal também abriga esses direitos em seus incisos I a XXXIV, alíneas e parágrafo único; artigo $8^{\circ}$, incisos I a VI e parágrafo único; artigo $9^{\circ}$ e parágrafos $1^{\circ}$ e $2^{\circ}$; bem como nos artigos 10 e 11 .

Diante desse contexto, perceptível é que esses direitos, tidos por direitos fundamentais de segunda geração, demandam absoluta prestação estatal, que, quando não proporcionados, resultam em um verdadeiro Estado de Coisas Inconstitucional, conforme será demonstrado.

\section{O ESTADO DE COISAS INCONSTITUCIONAL}

O Estado de Coisas Inconstitucional consiste em situação extrema de omissão estatal, configurada como "falhas estruturais". Essas falhas nada têm a ver com dispositivos constitucionais específicos ou ordens expressas de legislar ou de regulamentação, e sim com a omissão ou ineficiência do aparato estatal que resulta na proteção deficiente de direitos fundamentais. Consiste, assim, na inércia do Estado em promover a entrega daqueles direitos que envolvem prestações positivas de sua parte, os direitos sociais, classificados pela doutrina como direitos fundamentais de segunda geração (CAMPOS, 2016, p. 58).

A esse respeito, Campos (2016, p. 58-59) esclarece que:

[...] a questão é de atuação da norma constitucional, não de estrutura dos enunciados normativos; o problema é de efetividade de direitos fundamentais, não de eficácia jurídico-formal dos dispositivos constitucionais; o escopo deve ser a concretização da Constituição como um todo, não de preceitos constitucionais particulares.

Verifica-se, na teoria do Estado de Coisas Inconstitucional, uma solução adotada pelo Poder Judiciário ao constatar que a falta de proteção dos direitos fundamentais decorre de 
falhas estruturais do Estado contra as quais emite ordens às autoridades administrativas com o intuito de remediar a situação inconstitucional, determinando a implementação de políticas públicas que devem ser aplicadas para garantir os direitos fundamentais violados (PÁEZ, 2012, p. 244).

A referida teoria pode ser definida como um mecanismo ou técnica criada pelo Poder Judiciário por meio da qual declara que certas situações são contrárias à Constituição, devido a uma enorme violação de direitos e princípios consagrados em seu texto, determinando, por conseguinte, às autoridades competentes que, no quadro das suas funções e dentro de um prazo razoável, adotem as medidas necessárias para corrigir ou superar tal estado de coisas (LYONS; MONTERROZA; MEZA, 2011, p. 72).

\subsection{ORIGEM: CORTE CONSTITUCIONAL COLOMBIANA}

O jurista colombiano, Quintero (2014, p. 57), ao discorrer sobre o Estado de Coisas Inconstitucional, pontua que, infelizmente, no contexto Colombiano, os ideais pregados pelo Estado e abarcados pela Constituição Política da Colômbia esbarram em uma difícil realidade, complicada de subjugar.

Sobre essa situação, Ariza (2000, p. 966) complementa acrescentando que:

Vemos entonces como en nuestro país, la realidad social en donde apenas tienen vigencia los derechos básicos convive con una amplia normatividad garantista y generosa en su consagración. Los jueces, en nuestro caso la Corte Constitucional, se han visto enfrentados a un texto que desde arriba intent imponerse a las condiciones sociales y a las posibilidades políticas y sociales que lo niegan.

Diante dessa dicotomia, o Tribunal Constitucional colombiano precisou empregar uma abordagem que enfrentasse as situações pelas quais os direitos constitucionais eram violados de forma sistemática pelas instituições do Estado, o que resultou na criação da teoria do Estado de Coisas Inconstitucional.

A teoria decorre, assim, de construção jurisprudencial da Corte Constitucional colombiana, que tratou do assunto pela primeira vez na Sentencia de Unificación (SU) no 559, de 1997 (COLÔMBIA, 1997). Nesse caso, a Corte Constitucional constatou existir um descumprimento generalizado dos direitos previdenciários de um grupo de professores, oportunidade na qual declarou o "Estado de Coisas Inconstitucional" e determinou que os municípios envolvidos encontrassem solução para a inconstitucionalidade em prazo razoável.

Assim, resolveu a situação decidindo da seguinte forma:

Primero.- DECLARAR que el estado de cosas que originó las acciones de tutela materia de esta revisión no se aviene a la Constitución Política, por las razones expuestas en esta providencia. Como, al parecer, la situación descrita se presenta en muchos municipios, se advierte a las autoridades competentes que tal estado de cosas deberá corregirse dentro del marco de las funciones que a ellas atribuye la ley, en un término que sea razonable. Segundo.- ORDENAR que para los efectos del numeral primero se envíe copia de esta sentencia al Ministro de Educación, al Ministro de Hacienda y Crédito Público, al Director del 
Departamento Nacional de Planeación y a los demás miembros del CONPES Social; a los Gobernadores y las Asambleas Departamentales; y a los Alcaldes y los Concejos Municipales. Tercero.- En consecuencia, REVOCAR los fallos proferidos por el Juzgado Segundo Penal del Circuito de Cartagena y por el Juzgado Civil del Circuito de Carmen de Bolívar, los días 28 y 30 de octubre de 1996, respectivamente. En su lugar, se CONCEDE a los demandantes la tutela de su derecho a la igualdad. En consecuencia, los municipios demandados deberán, dentro del año siguiente a partir del primero $\left(1^{\circ}\right)$ de enero de 1998 , adelantar y culminar el trámite de afiliación de los actores al Fondo Nacional de Prestaciones Sociales del Magisterio (COLÔMBIA, 1997, on-line, grifo do auto).

Na esteira desse entendimento jurisprudencial, a Corte colombiana passou a pacificar a existência do "Estado de Coisas Inconstitucional" em decisões posteriores, tendo por maior destaque o caso que tratou na Sentencia de Tutela (T) no 153, de 1998 (COLÔMBIA, 1998) na qual referido entendimento foi aplicado pela Corte Constitucional em relação ao quadro de superlotação das penitenciárias do país, tendo em vista o descumprimento generalizado dos direitos fundamentais dos detentos. Tanto a superlotação quanto a violência nas penitenciárias eram mazelas nacionais recorrentes, de responsabilidade de um conjunto de autoridades. Dessa forma, além de declarar o "Estado de Coisas Inconstitucional”, ordenou a elaboração de um plano de construção e reparação das unidades carcerárias e determinou a alocação de recursos orçamentários necessários.

A decisão configurou-se, em trechos selecionados, da seguinte forma:

Primero.- ORDENAR que se notifique acerca de la existencia del estado de cosas inconstitucional en las prisiones al Presidente de la República; a los presidentes del Senado de la República y de la Cámara de Representantes; a los presidentes de la Sala Penal de la Corte Suprema Justicia y de las Salas Administrativa y Jurisdiccional Disciplinaria del Consejo Superior de la Judicatura; al Fiscal General de la Nación; a los gobernadores y los alcaldes; a los presidentes de las Asambleas Departamentales y de los Concejos Distritales y Municipales; y a los personeros municipales [...] Tercero.- ORDENAR al INPEC, al Ministerio de Justicia y del Derecho y al Departamento Nacional de Planeación elaborar, en un término de tres meses a partir de la notificación de esta sentencia, un plan de construcción y refacción carcelaria tendente a garantizar a los reclusos condiciones de vida dignas en los penales. La Defensoría del Pueblo y la Procuraduría General de Nación ejercerán supervigilancia sobre este punto. Además, con el objeto de poder financiar enteramente los gastos que demande la ejecución del plan de construcción y refacción carcelaria, el Gobierno deberá realizar de inmediato las diligencias necesarias para que en el presupuesto de la actual vigencia fiscal y de las sucesivas se incluyan las partidas requeridas. Igualmente, el Gobierno deberá adelantar los trámites requeridos a fin de que el mencionado plan de construcción y refacción carcelaria y los gastos que demande su ejecución sean incorporados dentro del Plan Nacional de Desarrollo e Inversiones. Cuarto.- ORDENAR al Ministerio de Justicia y del Derecho, al INPEC y al Departamento Nacional de Planeación, en cabeza de quien obre en cualquier tiempo como titular del Despacho o de la Dirección, la realización total del plan de construcción y refacción carcelaria en un término máximo de cuatro años, de conformidad con lo establecido en el Plan Nacional 
de Desarrollo e Inversiones. [...] Undécimo.- ORDENAR al Presidente de la República, como suprema autoridad administrativa, y al Ministro de Justicia y del Derecho que, mientras se ejecutan las obras carcelarias ordenadas en esta sentencia, tomen las medidas necesarias para garantizar el orden público y el respeto de los derechos fundamentales de los internos en los establecimientos de reclusión del país (COLÔMBIA, 1998, on-line, grifo do auto).

Por meio dessa postura adotada pela Corte Constitucional Colombiana, verifica-se que o chamado Estado de Coisas Inconstitucional não se limita apenas à declaração de que determinada situação não atende ao preenchimento dos direitos sociais previstos na Constituição, mas vai além, determinando prestações positivas do Estado por meio de ordens aos demais poderes, atribuindo-lhes, inclusive, prazos para o seu cumprimento.

\subsection{APLICAÇÃO NO PERU}

Avaliando os fundamentos do Estado de Coisas Inconstitucional, o Tribunal Constitucional peruano também efetuou a sua aplicação em julgamento de Habeas Data - Expediente n. 2579-2003-HD/TC - que ficou conhecido como caso Arellano Serquén.

$\mathrm{Na}$ oportunidade, a não manutenção da requerente em cargo público, exercido junto ao Distrito de Lamabayeque, foi o que originou a impetração do remédio constitucional contra o Conselho Nacional da Magistratura, para fins de que fosse fornecido: (i) o relatório da Comissão Permanente de Avaliação e Ratificação sobre a conduta do impetrante no exercício da função; (ii) cópia de sua entrevista pessoal; e (iii) cópia da decisão que entendeu pela descontinuidade no cargo.

Diante do pedido, assim decidiu o Tribunal peruano:

1. Declarar FUNDADA la acción de hábeas data.

2. Ordena que se entregue a la recurrente: a) copia del Informe de la Comisión Permanente de Evaluación y Ratificación, referente a su conducta e idoneidad en el cargo que ejercía como Vocal Superior de la Corte Superior de Justicia de Lambayeque; b) copia del acta de la entrevista personal y copia del vídeo de la referida entrevista personal; y c) copia de la parte pertinente del acta de sesión del Pleno del Consejo Nacional de la Magistratura que contiene la decisión de no ratificarla en su condición de Magistrada del Poder Judicial.

3. Declárese que el estado de cosas que originó el hábeas data, y que ha sido objeto de la controversia en este proceso, es contrario a la Constitución Política del Perú. 4. Remítase, por Secretaría General del Tribunal Constitucional, la presente sentencia a los miembros del Consejo Nacional de la Magistratura, a fin de que en un plazo de 90 días hábiles a partir de la notificación de ésta, adopten las medidas necesarias y adecuadas a fin de corregir, dentro de los parámetros constitucionales, las solicitudes de entrega de información sobre el proceso de ratificación judicial.

5. Prevéngase a los consejeros del Consejo Nacional de la Magistratura para que eviten volver a incurrir en las acciones u omisiones ilegítimas que origi- 
naron el presente proceso, de conformidad con lo expuesto en el Fundamento Jurídico N. ${ }^{\circ} 21$.

6. Dispone que las medidas que se adopten se pongan en conocimiento del juez de ejecución de la sentencia, quien, al décimo (10) día hábil de culminado el plazo otorgado en la presente, informará a la Secretaría General del Tribunal Constitucional.

Publíquese y notifíquese (PERU, 2017, on-line).

Assim, a declaração do Estado de Coisas Inconstitucional ocorreu diante do raciocínio de que a violação do direito da impetrante (obtenção de documentos) foi sustentada em âmbito de violação constitucional, tendo em vista que o estado de coisas que originou o Habeas Data é incompatível com a Constituição.

A versão peruana do ECI exclui a ideia de violação "maciça" dos direitos fundamentais de outras pessoas que não são parte do processo, adotando um único propósito: a eficácia ultra partes da tutela dos direitos fundamentais, para os quais basta verificar a afetação homogênea aos direitos de outras pessoas que não fazem parte do processo (ARMAS, 2010, p. 142).

Sob essa abordagem, a relevância de se identificar um problema estrutural é mínima, podendo-se afirmar que se trata de uma versão atenuada da declaração de ECI colombiana.

\subsection{APLICAÇÃO NO BRASIL}

Essa linha de entendimento traçada pela Corte colombiana e também já aplicada pelo Tribunal Constitucional peruano, ganhou destaque, causando repercussão no meio jurídico, passando a influenciar de forma robusta, inclusive, os juristas pátrios.

O Supremo Tribunal Federal até então se posicionava com entendimento que privilegiava a teoria da reserva do possível.

Essa teoria tem por escopo viabilizar ao Estado justificativas aceitáveis para o não cumprimento de políticas públicas, uma vez que legitima que direitos constitucionais dos cidadãos, como os sociais, por exemplo, não devam necessariamente ser observados.

Referida teoria é proveniente do Direito germânico, que se materializou por meio de um caso julgado pelo Tribunal Constitucional Federal, oportunidade na qual um cidadão pleiteou uma vaga no Ensino Superior público, sem se submeter a processo seletivo, alegando que, nos termos da lei, era detentor de direito de escolha de sua profissão, motivo pelo qual não poderia o Estado the restringir acesso ao curso superior (KRELL, 2002, p. 50-52).

Na oportunidade, para solução do conflito instaurado entre o demandante e o Estado, o Tribunal alemão desenvolveu e aplicou, pela primeira vez, a teoria da reserva do possível, resolvendo que a disponibilidade de determinados serviços públicos deve ser condicionada à disponibilidade de recursos e de meios do Estado, de forma que não se mostra sensato exigir prestações que fogem do juízo de razoabilidade. Com esses fundamentos, a demanda foi julgada improcedente (SARLET, 2008, p. 264). 
Referida tese ficou lá denominada de "Der Vorbehalt des Möglichen”3, que evoluiu para o princípio da reserva do possível no Brasil.

Verifica-se que, nesse julgamento pelo Tribunal Constitucional Federal alemão, a tese da reserva do possível foi inserida como um limitador ao cumprimento dos direitos sociais em função da própria escassez financeira estatal. Nesse sentido, Fercot (2010, p. 82) destaca que "this reserve is the main limit fixed to the 'rights to political participation' (Teilhaberechte), that is to what the individual has the right to 'reasonably' expected to the collectivity".

Segundo Sarlet (2008, p. 265), ao interpretar referido princípio, esclarece que mediante sua aplicação ao caso abordado alhures, houve o entendimento do Tribunal Alemão de que "a prestação reclamada deve corresponder ao que o indivíduo pode razoavelmente exigir da sociedade, de tal sorte que, mesmo em dispondo o Estado de recursos e tendo poder de disposição, não se pode falar em uma obrigação de prestar algo que não se mantenha nos limites do razoável.”

Tal posição doutrinária, que se vale da razoabilidade e da disposição de recursos financeiros, foi acolhida e sustentada por muito tempo pelo Supremo Tribunal Federal, conforme pode ser verificado por meio do julgamento da $\mathrm{ADPF}^{5}$ n. 45, oportunidade na qual a Suprema Corte confirmou a existência e a utilização da teoria da reserva do possível no ordenamento jurídico pátrio. A decisão se cristalizou, em trecho selecionado, com o seguinte teor:

[...] Vê-se, pois, que os condicionamentos impostos, pela cláusula da "reserva do possível", ao processo de concretização dos direitos de segunda geração - de implantação sempre onerosa -, traduzem-se em um binômio que compreende, de um lado, (1) a razoabilidade da pretensão individual/social deduzida em face do Poder Público e, de outro, (2) a existência de disponibilidade financeira do Estado para tornar efetivas as prestações positivas dele reclamadas. Desnecessário acentuar-se, considerado o encargo governamental de tornar efetiva a aplicação dos direitos econômicos, sociais e culturais, que os elementos componentes do mencionado binômio (razoabilidade da pretensão + disponibilidade financeira do Estado) devem configurar-se de modo afirmativo e em situação de cumulativa ocorrência, pois, ausentes quaisquer desses elementos, descaracterizar-se-á a possibilidade estatal de realização prática de tais direitos (BRASIL, 2004, on-line, grifo nosso).

Percebe-se que até então, por meio da teoria da reserva do possível, a jurisprudência do STF inclinava-se a consentir com a ineficácia do Estado no que tange ao cumprimento de suas obrigações constitucionais em relação aos direitos sociais.

3 "Reserva do potencial" (tradução nossa).

4 "A reserva é um meio de limitação estabelecida para os "direitos à participação política" (direitos fundamentais de segunda geração), isso é, o que o indivíduo tem direito de razoavelmente esperar da coletividade" (tradução nossa).

5 Medida cautelar em arguição de descumprimento de preceito fundamental. Medida prevista na Lei Federal 9.882/99. Em seu art. $5^{\circ}, \S 3^{\circ}$, dispõe que “A liminar poderá consistir na determinação de que juízes e tribunais suspendam o andamento de processo ou os efeitos de decisões judiciais, ou de qualquer outra medida que apresente relação com a matéria objeto da arguição de descumprimento de preceito fundamental, salvo se decorrente da coisa julgada.” (BRASIL, 1999, on-line). 
Todavia, influenciado pela teoria do Estado de Coisas Inconstitucional, assumiu expressamente esse entendimento quando do julgamento do RE $n^{\circ} 592.581$ e da ADPF n ${ }^{\circ} 347$.

Por meio do julgamento do RE no 592.581 , com repercussão geral, o Plenário do STF decidiu, em agosto de 2015, que é lícito ao Judiciário impor à Administração Pública obrigação de fazer, para fins de realização de obras ou reformas emergenciais em presídios para garantir os direitos fundamentais dos presos, como sua integridade física e moral. Tal decisão se materializou da seguinte forma:

Vistos, relatados e discutidos estes autos, acordam os Ministros do Supremo Tribunal Federal, em Sessão Plenária, sob a Presidência do Senhor Ministro Ricardo Lewandowski, na conformidade da ata de julgamentos e das notas taquigráficas, por unanimidade e nos termos do voto do Relator, apreciando o tema 220 da repercussão geral, dar provimento ao recurso extraordinário para cassar o acórdão recorrido, a fim de que se mantenha a decisão proferida pelo juízo de primeiro grau. Ainda por unanimidade, assentar a seguinte tese: "É lícito ao Judiciário impor à Administração Pública obrigação de fazer, consistente na promoção de medidas ou na execução de obras emergenciais em estabelecimentos prisionais para dar efetividade ao postulado da dignidade da pessoa humana e assegurar aos detentos o respeito à sua integridade física e moral, nos termos do que preceitua o art. $5^{\circ}$, XLIX, da Constituição Federal, não sendo oponível à decisão o argumento da reserva do possível nem o princípio da separação dos poderes". Ausente, justificadamente, o Ministro Teori Zavascki (BRASIL, 2015a, on-line, grifo nosso).

Mas foi, na oportunidade do julgamento da Medida Cautelar na ADPF no 347, que o Supremo Tribunal Federal sinalizou pelo efetivo reconhecimento do Estado de Coisas Inconstitucional.

Ajuizada pelo Partido Socialismo e Liberdade (PSOL), pleiteava, a exemplo do que havia ocorrido na Colômbia, o reconhecimento da violação de direitos fundamentais da população carcerária e que fosse determinada a adoção de diversas providências no tratamento da questão prisional do país.

Assim, a Suprema Corte se manifestou:

Vistos, relatados e discutidos estes autos, acordam os Ministros do Supremo Tribunal Federal em, apreciando os pedidos de medida cautelar formulados na inicial, por maioria e nos termos do voto do Relator, deferir a cautelar em relação à alínea "b", para determinar aos juízes e aos tribunais que, observados os artigos 9.3 do Pacto dos Direitos Civis e Políticos e 7.5 da Convenção Interamericana de Direitos Humanos, realizem, em até noventa dias, audiências de custódia, viabilizando o comparecimento do preso perante a autoridade judiciária no prazo máximo de 24 horas, contados do momento da prisão, com a ressalva do voto da Ministra Rosa Weber, que acompanhava o Relator, mas com a observância dos prazos fixados pelo Conselho Nacional de Justiça - CNJ, vencidos, em menor extensão, os Ministros Teori Zavascki e Roberto Barroso, que delegavam ao $\mathrm{CNJ}$ a regulamentação sobre o prazo da realização das audiências de custódia; em relação à alínea "h", por maioria e nos termos do voto do Relator, em deferir a cautelar para determinar à União que libere o saldo acumulado do Fundo Penitenciário Nacional para utilização com a finalida- 
de para a qual foi criado, abstendo-se de realizar novos contingenciamentos, vencidos, em menor extensão, os Ministros Edson Fachin, Roberto Barroso e Rosa Weber, que fixavam prazo de até sessenta dias, a contar da publicação desta decisão, para que a União procedesse à adequação para o cumprimento do que determinado; em indeferir as cautelares em relação às alíneas "a", "c" e "d", vencidos os Ministros Relator, Luiz Fux, Cármen Lúcia e o Presidente, que as deferiam; em indeferir em relação à alínea "e", vencido, em menor extensão, o Ministro Gilmar Mendes; e, por unanimidade, em indeferir a cautelar em relação à alínea "f"; em relação à alínea "g", por maioria e nos termos do voto do Relator, o Tribunal julgou prejudicada a cautelar, vencidos os Ministros Edson Fachin, Roberto Barroso, Gilmar Mendes e Celso de Mello, que a deferiam nos termos de seus votos. O Tribunal, por maioria, deferiu a proposta do Ministro Roberto Barroso, ora reajustada, de concessão de cautelar de ofício para que se determine à União e aos Estados, e especificamente ao Estado de São Paulo, que encaminhem ao Supremo Tribunal Federal informações sobre a situação prisional, vencidos os Ministros Marco Aurélio, Relator, que reajustou o voto, e os Ministros Luiz Fux, Cármen Lúcia e Presidente, em sessão presidida pelo Ministro Ricardo Lewandowski, na conformidade da ata do julgamento e das respectivas notas taquigráficas (BRASIL, 2015b, on-line, grifo nosso).

Nesse contexto, verifica-se que o STF passa a seguir o entendimento consolidado pela Corte colombiana, compreendendo os referidos conceitos a partir da Declaração do Estado de Coisas Inconstitucional, em função do qual passa a determinar que os outros poderes do Estado assumam prestações positivas para fins de entrega dos direitos sociais aos seus cidadãos.

Diante dessa conjuntura, muitos questionamentos tornam-se evidentes, entre eles, destacam-se os seguintes: Cabe ao Poder Judiciário determinar os demais poderes do Estado como e quando exercerem suas atribuições constitucionais? O Poder Judiciário possui competência técnica e legitimidade para resolver de forma democrática, com eficiência e equidade as políticas públicas a serem realizadas?

\section{A INVIABILIDADE DO ESTADO DE COISAS INCONSTITUCIONAL}

As mudanças ocorridas nas ordens constitucionais após a Segunda Guerra Mundial tornaram possível a valorização do Poder Judiciário como poder estatal capaz de solucionar muitos conflitos presentes no âmbito social, político e jurídico (PONTES; GOMES NETO; TEIXEIRA, 2017, p. 139).

Soma-se a isso o fato de os direitos fundamentais, estipulados nas Constituições Políticas, constituírem precisamente uma limitação ao princípio de maiorias, com a garantia mínima de direitos de minorias e indivíduos em condições de fraqueza ou vulnerabilidade. Em outras palavras, o juiz, diante de um Estado de Coisas Inconstitucional, pode se curvar às minorias, grupos esquecidos, que apresentam dificuldade em ter acesso aos direitos sociais (ZAMBRANO, 2016, p. 93).

No entanto, podem-se construir várias críticas em relação à teoria. Nesse viés, Vélez e Escobar (2016, p. 251) apontam que o Poder Judiciário adota uma abordagem gerencial, 
por meio da qual a solução efetiva dos problemas que afligem a população em relação aos seus direitos fundamentais é substituída por declarações retóricas, por simples declarações de princípios.

Nesse sentido, não haverá sustentabilidade na resolução dos problemas por meio de decisões judiciais, tendo em vista que as medidas efetivas serão pontuais, tornando as declarações de Estado de Coisas Inconstitucional meros discursos, que não trarão efetividade para a maioria das pessoas.

Assim, o reconhecimento do Estado de Coisas Inconstitucional pelo Poder Judiciário, com a respectiva imposição de obrigações de fazer aos demais poderes do Estado, mostra-se inviável, tendo em vista a carga de irracionalidade que recai sobre essa situação, em função da falta de eficiência de que podem estar revestidas as decisões, uma vez que não consideram as externalidades negativas que podem proporcionar.

O Estado de Coisas Inconstitucional pressupõe desvio da democracia, um dos fundamentos da República Federativa do Brasil, tendo em vista que cabe aos representantes eleitos pelo povo a prerrogativa de definição das prioridades sobre os gastos públicos, e não ao Poder Judiciário, o que consiste na prática denominada pela doutrina de ativismo judicial.

Essa prática pelo Judiciário busca, por meio da hermenêutica jurídica, concretizar o verdadeiro valor normativo constitucional, garantindo o direito das partes de forma rápida e atendendo às soluções dos litígios e às necessidades oriundas da lentidão ou omissão legislativa e do executivo.

O jurista Ramos (2010, p. 129) trata o ativismo judicial com base na intervenção do Judiciário nas outras esferas de poder, definindo-o como o exercício da função jurisdicional para "além dos limites impostos pelo próprio ordenamento que incumbe, institucionalmente, ao Poder Judiciário fazer atuar, importando na desnaturação da atividade típica do Poder Judiciário, em detrimento dos demais Poderes."

Streck $(2014$, p. 50) também esclarece que, quando o Judiciário atua fora da órbita, para a qual foi originariamente legitimado, será ativista, pois estará agindo fora dos limites impostos pela autonomia do Direito.

Assim, o resultado disso é o agigantamento do poder atribuído ao Judiciário, por meio da legitimação da atuação pautada em exacerbado subjetivismo, que afasta as bases contidas no sistema jurídico, de forma a proporcionar o surgimento de uma ditadura do Poder Judiciário, que passa a invadir a esfera de competência dos outros Poderes constituídos (CARMO; MESSIAS, 2017, p. 198).

Esse ativismo judicial resulta em enfraquecimento da democracia, pois possibilita ao Poder Judiciário estabelecer as prioridades sobre os gastos públicos, o que é inconcebível, haja vista a destinação dos recursos públicos caber aos representantes eleitos pelo povo.

$\mathrm{O}$ enfraquecimento da democracia resultará em externalidades negativas, tendo em vista que, no cenário econômico e político internacional, pode repercutir negativamente, exteriorizando a sobreposição das atribuições entre os poderes do Estado, o que resulta na 
ausência de segurança jurídica. Isso gera incertezas, bem como afasta os investimentos estrangeiros, além de atrapalhar negociações comerciais internacionais, o que é inadmissível perante o sistema de referência proposto.

Tem-se, ainda, que o reconhecimento do Estado de Coisas Inconstitucional não observa a eficiência que deve ser perseguida pelo Estado. Os agentes administrativos são assistidos por profissionais competentes e qualificados para a tomada de decisões, e seus cargos pressupõem esse assessoramento técnico. Nesse ínterim, esse contexto possibilita a eles condiçõoes de tomarem as melhores decisões para a aplicação dos recursos públicos, levando-se em consideração, também, que, em função da posição que ocupam, possuem uma visão mais ampla de todo o cenário político, econômico e social, o que lhes possibilita um melhor direcionamento dos recursos, a fim de implementar a política pública mais adequada para o momento.

Dessa forma, os magistrados, via de regra, não possuem assessoramento técnico para decidir frente à necessidade de implementação de políticas públicas que, por vezes, são revestidas de complexidade. No mais, o processo judicial, em função de suas peculiares limitações, não pressupõe o ambiente adequado para intervenções dessa natureza, de modo que as decisões judiciais, ainda que bem intencionadas, podem prejudicar, ao invés de promover a efetivação dos direitos sociais, situação que não encontra amparo perante a análise econômica do Direito, uma vez que se vislumbra a possibilidade de ocorrência de inúmeras externalidades negativas.

Há que se destacar, ainda, a assimetria gerada pelo Estado de Coisas Inconstitucional, pois, da forma como posto, proporciona a efetivação dos direitos sociais apenas àqueles que possuem acesso à justiça. Tal situação, se persistir, resultará na canalização dos recursos escassos (destinados às políticas públicas) para atender às demandas daqueles que possuem acesso à justiça, os que são mais assistidos juridicamente, o que pode proporcionar o efeito inverso, agravando a injustiça social, em vez de amenizá-la.

A principal função do Poder Judiciário em relação à legislação constitucional é permanecer como um fórum de princípios, e não como um espaço para o debate de interesses particulares (ZAMBRANO, 2012, p. 31).

Imagine a situação em que um indivíduo, na busca de tratamento de saúde, ajuíze ação individual em busca da declaração do Estado de Coisas Inconstitucional para fins de obter medida de urgência que determine ao Estado o custeio de seu tratamento no exterior, acarretando despesas milionárias aos cofres públicos. Ao refletir sobre essa circunstância, utilizando-se da hermenêutica proposta pela análise econômica do Direito, conclui-se que os valores utilizados para o custeio do tratamento de uma única pessoa resultarão na ausência de recursos na rede pública de saúde para o acompanhamento terapêutico de centenas de outras pessoas.

Soma-se a isso que a busca dos direitos sociais, por meio do Poder Judiciário, caminha na contramão da eficiência, pois gera inúmeras externalidades em função dos gastos de recursos 
e energia em demandas judiciais, quando poderiam ser direcionados para o desenvolvimento econômico, situação que é inconcebível perante o sistema de referência adotado.

Nesse sentido, Rodrigues (2016, p. 441) pontua a importância da adoção de medidas estruturais que sejam efetivadas por meio de um diálogo institucional, de forma a preservar a competência e a vocação constitucional de cada Poder.

A entrega dos direitos fundamentais à população, por meio da declaração do Estado de Coisas Inconstitucional, beneficia alguns poucos indivíduos que tiveram acesso à justiça, o que é totalmente oposto à sustentabilidade das medidas a serem perseguidas pelo Estado que, entre suas funções, deve proporcionar os referidos direitos a todos, indistintamente.

A aplicação da teoria do ECI é reprovada pela análise econômica do Direito, pois as decisões por ela amparadas são revestidas de irracionalidade, o que resulta em soluções pontuais diante da amplitude dos problemas sociais comuns aos países em desenvolvimento, ocasionando externalidades negativas de proporções muito superiores às soluções que se tentou encontrar.

\section{CONCLUSÃO}

A declaração do denominado Estado de Coisas Inconstitucional pelo Poder Judiciário, como ocorreu na Colômbia e recentemente também no Brasil, não consiste apenas no reconhecimento de que os direitos sociais assegurados pela Constituição não estão sendo entregues aos cidadãos, mas também na imposição de obrigações de fazer aos demais poderes do Estado.

Todavia, conclui-se que essa linha de entendimento do Poder Judiciário acaba por gerar incontáveis externalidades negativas, o que é veementemente reprovado pelo sistema de referência que leva em consideração o necessário diálogo entre Direito e Economia.

Isso porque, conforme ficou demonstrado, essa postura do Poder Judiciário resulta no enfraquecimento da democracia, na inobservância da eficiência da administração pública e em assimetria na implementação das políticas públicas, situações que geram externalidades negativas que não podem ser mensuradas por esse poder.

Conclui-se, então, que a declaração do Estado de Coisas Inconstitucional resulta no enfraquecimento da democracia em função das decisões administrativas serem tomadas pelo Poder Judiciário, e não pelos representantes do povo legitimamente eleitos, o que gera insegurança aos olhos do mundo, sendo certo que resultará em externalidades negativas em função da falta de confiança e de descrédito no cenário internacional.

As nações estrangeiras e os investidores em geral levam em consideração os ideais políticos que foram aceitos pela maioria da população, com a escolha de seus representantes por meio do voto, de forma que, ao passar a tomar decisões de cunho administrativo, as quais cabem ao Poder Executivo, o Judiciário gerará incertezas e insegurança jurídica, o que é condenável sob os aspectos econômicos e o enfoque da sustentabilidade. 
Conclui-se, também, que o Poder Judiciário não possui conhecimento técnico para resolver pela implementação de políticas públicas, o que certamente resultará em ineficiência de suas decisões, com consequentes e óbvias externalidades negativas. $\mathrm{O}$ estabelecimento forçado de determinada política pode, por exemplo, resultar na falta de recursos para a inserção de outra política de cunho emergencial, acabando por gerar externalidades negativas muito mais impactantes diante do contexto global.

Frise-se, ainda, em conclusão, a assimetria a que pode se sujeitar a implementação das políticas públicas, tendo em vista que terão preferências as necessidades das pessoas e dos grupos que possuem acesso à justiça, o que certamente resultará no agravamento da injustiça social, em vez de sua amenização, o que ocasiona um custo muito maior a médio e a longo prazo, produzindo externalidades negativas que perdurarão no tempo.

Dessa forma, conclui-se que a teoria do Estado de Coisas Inconstitucional, a qual legitima ao Poder Judiciário impor obrigações de fazer aos demais poderes do Estado, resulta na produção de incontáveis externalidades negativas, que inclusive não podem ser mensuradas por esse Poder, o que contraria a concepção de que deve haver estreito diálogo entre o Direito e a Economia, motivo pelo qual não é válido perante o sistema de referência proposto no presente estudo.

\section{REFERÊNCIAS}

ARAÚJO, Luiz Alberto David; NUNES JÚNIOR, Vidal Serrano. Curso de Direito Constitucional. São Paulo: Saraiva, 1999.

ARIZA, José Libardo. La Realidad contra el Texto: Una Aproximación al Estado de Cosas Inconstitucional. Revista tutela, acciones populares y de cumplimiento, Santa Fe de Bogotá, v. 4, n. 1, p. 965-978, 2000.

ARMAS, Renato Vásquez. La técnica de declaración del "Estado de cosas Inconstitucional": fundamentos y análisis de su aplicación por el Tribunal Constitucional Peruano. IUS ET VERITAS: Revista de la Asociación IUS ET VERITAS, n. 41, p. 128-147, 2010.

BRASIL. [Constituição (1988)]. Constituição da República Federativa do Brasil de 1988. Brasília, DF: Presidência da República, 1988. Disponível em: http://www.planalto.gov.br/ ccivil_03/Constituicao/Constituiçao.htm. Acesso em: 17 jul. 2017.

BRASIL. Lei no 9.882, de 3 de dezembro de 1999. Dispõe sobre o processo e julgamento da argüição de descumprimento de preceito fundamental, nos termos do $\S 1^{\circ}$ do art. 102 da Constituição Federal. Brasília, DF: Presidência da República, 1999. Disponível em: http://www.planalto.gov.br/ccivil_03/LEIS/L9882.htm. Acesso em: 17 jul. 2017.

BRASIL. Supremo Tribunal Federal. ADPF 45 MC/DF. Medida cautelar em arguição de descumprimento de preceito fundamental. Rel.: Min. Celso de Mello. Julgamento: 29/04/2004.

Disponível em: https://stf.jusbrasil.com.br/jurisprudencia/14800508/medida-cautelar-em-arguicao-de-descumprimento-de-preceito-fundamental-adpf-45-df-stf. Acesso em: 8 jun. 2017. 
BRASIL. Supremo Tribunal Federal. Recurso extraordinário 592.581. Rel.: Min. Ricardo Lewandowski. Julgamento: 13/08/2015. 2015a. Disponível em: http://redir.stf.jus.br/paginadorpub/paginador.jsp?docTP=TP\&docID=10166964. Acesso em: 17 jul. 2017.

BRASIL. Supremo Tribunal Federal. ADPF 347 MC/DF. Medida Cautelar em arguição de descumprimento de preceito fundamental. Rel.: Min. Marco Aurélio. Julgamento: 09/09/2015. 2015b. Disponível em: http://redir.stf.jus.br/paginadorpub/paginador. jsp?docTP=TP\&docID=10300665. Acesso em: 17 jul. 2017.

CAMPOS, Carlos Alexandre de Azevedo. Estado de Coisas Inconstitucional. Salvador: Juspodivm, 2016.

CARMO, Valter Moura; MESSIAS, Ewerton Ricardo. Pós-modernidade e principiologia jurídica: o ativismo judicial e sua validade no âmbito do Estado Democrático de Direito. Revista Brasileira de Direito, Passo Fundo, v. 13, n. 3, p. 189-205, set./dez. 2017.

COASE, R. H. The Problem of Social Cost.The Journal of Law e Economics, Chicago, v. 3, p. 1-44, 1960. Disponível em: http://www.jstor.org/stable/724810?origin=JSTOR-pdf\&seq=1\#page_scan_tab_contents. Acesso em: 16 jul. 2017.

COLÔMBIA. Corte Constitucional de Colombia. Sentencia SU.559/97. 1997. Disponível em: http://www.corteconstitucional.gov.co/RELATORIA/1997/SU559-97.htm. Acesso em: 17 jul. 2017.

COLÔMBIA. Corte Constitucional de Colombia. Sentencia T-153/98. 1998. Disponível em: http://www.corteconstitucional.gov.co/relatoria/1998/t-153-98.htm. Acesso em: 17 jul. 2017.

DALLARI, Dalmo de Abreu. Direitos Humanos e Cidadania. São Paulo: Moderna, 2004. DIAS, Jefferson Aparecido. Princípio da eficiência $\&$ moralidade administrativa: a submissão do princípio da eficiência à moralidade administrativa na Constituição Federal de 1988. Curitiba: Juruá, 2009.

FERCOT, Céline. The Improbable Justiciability of Social Rights in Germany and Switzerland. In: EUI Working Papers. Diversity of social rights in Europe, rights of the poor, the poor rights. University Paris, Oueste Natenrre - European University Institute Social Law Working Group. 2010. p. 71-97. Disponível em: http://cadmus.eui.eu/bitstream/handle/1814/14739/LAW_2010_07.pdf. Acesso em: 15 jun. 2017.

KRELL, Andreas Joachim. Direitos Sociais e Controle Judicial no Brasil e na Alemanha: os (des) caminhos de um direito constitucional comparado. Porto Alegre: Sergio Antonio Fabris Editor, 2002.

LYONS, Josefina Quintero; MONTERROZA, Angélica Matilde Navarro; MEZA, Malka Irina. La figura del estado de cosas inconstitucionales como mecanismo de protección de los derechos fundamentales de la población vulnerable en Colombia. Revista Mario Alario D’Filippo, v. 3, n. 1, p. 69-80, 2011. 
MOTTA, Ronaldo Seroa da. Manual para valoração econômica de recursos ambientais. IPEA/MMA/PNUD/CNPq. Rio de Janeiro, set. 1997. Disponível em: http://www.terrabrasilis.org.br/ecotecadigital/pdf/manual-para-valoracao-economica-de-recursos-ambientais.pdf. Acesso em: 16 jul. 2017.

NUSDEO, Ana Maria de Oliveira. Pagamento por serviços ambientais: sustentabilidade e disciplina jurídica. São Paulo: Atlas, 2012.

NUSDEO, Fábio. Desenvolvimento e ecologia. São Paulo: Saraiva, 1975.

NUSDEO, Fábio. Curso de Economia: introdução ao direito Econômico. São Paulo: Revista dos Tribunais, 2015.

PÁEZ, Nicolás Augusto Romero. La doctrina del estado de cosas inconstitucional en Colombia: novedades del neoconstitucionalismo y "la inconstitucionalidad de la realidad".

Revista Derecho Público Iberoamericano, n. 1, p. 243-264, 2012.

PERU. Tribunal Constitucional. Expediente n 2579-2003-HD/TC. Disponível em: http:// www.tc.gob.pe/jurisprudencia/2004/02579-2003-HD.html. Acesso em: 10 nov. 2017.

PINHEIRO, Armando Castelar; SADDI, Jairo. Direito, Economia e Mercados. Rio de Janeiro: Elsevier, 2005.

PONTES, Juliana de Brito; GOMES NETO, José Mário Wanderley; TEIXEIRA, João Paulo Fernandes de Souza Allain. Autocontenção no Judiciário Brasileiro: uma análise das relações estratégicas entre os poderes constituídos do Estado. Revista Opinião Jurídica, Fortaleza, v. 15, n. 20, p. 138-159, jan./jun. 2017.

POSNER, Richard A. A economia da justiça. São Paulo: Martins Fontes, 2010.

QUINTERO, Pablo Daniel Hurtado. Justicia, derechos humanos y coraje de la verdad: El concepto problemático de estado de cosas inconstitucional como manifestación parrhesiástica. Nuevo derecho, v. 10, n. 15, p. 55-61, jul./dic. 2014.

RAMOS, Elival da Silva. Ativismo judicial: parâmetros dogmáticos. São Paulo: Saraiva, 2010.

RODRIGUES, Francisco Lisboa. Direito comparado e transjusfundamentalidade: o estado de coisas inconstitucional no STF. In: CAÚLA, Bleine Queiroz; ARRUDA, Gerardo Clésio Maia; CARMO, Valter Moura do (org.). Diálogo ambiental, constitucional e internacional. Rio de Janeiro: Lumen Juris, 2016. v. 6. p. 429-448.

SARLET, Ingo Wolfgang. A Eficácia dos Direitos Fundamentais. Porto Alegre: Livraria do Advogado, 2008.

SCHMIDT, Albano Francisco. Os primeiros 30 anos do fundo de defesa de direitos difusos sob a luz da análise econômica do direito: "contribuintes", projetos apoiados e novas perspectivas sociais. Argumentum, Marília, n. 15, p. 201-226, 2014. 
SILVA, José Afonso da. Curso de Direito Constitucional Positivo. São Paulo: Malheiros Editores, 2000.

STRECK, Lênio Luiz. Verdade e consenso. São Paulo: Saraiva, 2014.

VÉLEZ, Susana Escobar; ESCOBAR, Miguel Ricardo Medina. Sentencia de la Corte Constitucional T-762 de 2015, de dieciséis (16) de diciembre de dos mil quince (2015), sobre estado de cosas inconstitucional en el sistema penitenciario y carcelario en Colombia. Nuevo Foro Penal, n. 87, p. 244-251, 2016.

ZAMBRANO, Sonia Patricia Cortés. Poder discrecional de la corte constitucional en el estado de cosas inconstitucional. Via Inveniendi et Iudicandi, v. 7, n. 2, p. 57-78, 2012. ZAMBRANO, Sonia Patricia Cortés. La dimensión Jurídica del Estado de Cosas Inconstitucional en el caso de las víctimas del desplazamiento forzado en Colombia. Diálogos de saberes: investigaciones y ciencias sociales, n. 45, p. 89-106, 2016.

ZYLBERSZTAJN, Décio; STAJN, Rachel. Direito e economia: analise econômica do direito e das organizações. Rio de Janeiro: Campus Jurídico, 2005. 